\title{
The Italian Register of Cardiovascular Diseases: Attack Rates and Case Fatality for Cerebrovascular Events
}

\author{
L. Palmieri $^{\mathrm{a}} \quad$ A. Barchiellib ${ }^{\mathrm{b}} \quad$ G. Cesana ${ }^{\mathrm{C}} \quad$ E. de Camporad ${ }^{\mathrm{d}} \quad$ C.A. Goldoni ${ }^{\mathrm{e}}$

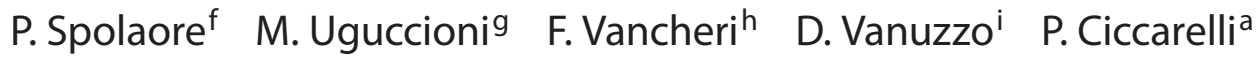 \\ S. Giampaolia ${ }^{a}$ on behalf of the Research Group of the Project 'Italian National \\ Register of Coronary and Cerebrovascular Events' \\ ${ }^{a}$ National Center for Epidemiology, Surveillance and Health Promotion, Institute of Health, Rome, \\ ${ }^{b}$ S.A. Epidemiologia ASL 10, Florence, 'Milano-Bicocca University, Monza, ${ }^{\mathrm{d}}$ Agenzia Regionale Sanitaria Campania, \\ Naples, ${ }^{e}$ Dipartimento di Sanità Pubblica AUSL, Modena, ${ }^{\mathrm{f}}$ Sistema Epidemiologico Regionale, Treviso, \\ ${ }^{g}$ Ospedale CTO A. Alesini, Rome, ${ }^{\mathrm{h}} \mathrm{Az}$. Ospedaliera S. Elia, Caltanissetta, and ${ }^{\mathrm{i} C a r d i o v a s c u l a r}$ Prevention Center, \\ Udine, Italy
}

\section{Key Words \\ Population-based register $\cdot$ Attack rate $\cdot$ Case fatality rate}

\begin{abstract}
Background: The Italian register of cardiovascular diseases is a surveillance system of fatal and nonfatal cardiovascular events in the general population aged 35-74 years. It was launched in Italy at the end of the 1990s with the aim of estimating periodically the occurrence and case fatality rate of coronary and cerebrovascular events in the different geographical areas of the country. This paper presents data for cerebrovascular events. Methods: Current events were assessed through record linkage between two sources of information: death certificates and hospital discharge diagnosis records. Events were identified through the ICD codes and duration. To calculate the number of estimated events, current events were multiplied by the positive predictive value of each specific mortality or discharge code derived from the validation of a sample of suspected events. Attack rates were calculated by dividing estimated events by resident population, and case fatality rate at 28 days was determined
\end{abstract}

\section{KARGER \\ Fax +41613061234 \\ E-Mail karger@karger.ch}

www.karger.com

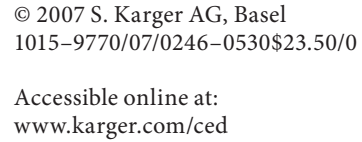

from the ratio of estimated fatal to total events. Results: Attack rates were found to be higher in men than in women: mean age-standardized attack rate was 21.9/10,000 in men and 12.5/10,000 in women; age-standardized 28-day case fatality rate was higher in women (17.1\%) than in men (14.5\%). Significant geographical differences were found in attack rates of both men and women. Case fatality was significantly heterogeneous in both men and women. Conclusions: Differences still exist in the geographical distribution of attack and case fatality rates of cerebrovascular events, regardless of the north-south gradient. These data show the feasibility of implementing a population-based register using a validated routine database, necessary for monitoring cardiovascular diseases.

Copyright $\odot 2007$ S. Karger AG, Basel

\section{Introduction}

Stroke represents a leading cause of death and disability. In 2002, cerebrovascular diseases accounted for about $12 \%$ of all causes of mortality in Italy [1]; they have been 
decreasing since the 1970s [2]. Even though a north-south gradient is not evident, the phenomenon appears with greater intensity in some areas: until the mid 1980s, mortality was found to be higher among men in the north of Italy; subsequently, it increased in the south of Italy, and higher values were constantly found among women in the south of Italy [2].

Stroke clinically manifests itself in older age after many years of exposure to unhealthy lifestyles and risk factors [3]. Even though clinical onset is mainly acute, stroke often evolves gradually and causes substantial loss of quality of life, disability, and lifelong dependence on health services and medications. The societal costs of stroke are huge and they are not only those directly related to health care and social services, but also include those linked to disability pension, impact on families and caregivers and to loss of years of productive life.

Therefore, there is a need to plan primary and secondary prevention, rehabilitation services, family support, and to allocate resources in the community. To achieve this, it is necessary to implement an effective surveillance system capable of providing stable and reliable indicators such as attack and case fatality rates, which are recommended to assess the impact of the disease in the community $[4,5]$.

In the late 1990s, experiences were documented in Italy in the Aosta Valley region [6] and in the city ofl'Aquila $[7,8]$, where registers including in- and out-of hospital events were implemented. Hospitalized events in these areas were collected; then severity and outcome were assessed through a detailed morbidity and mortality follow-up. Unfortunately, these experiences were limited and sometimes the number of events registered in 1 year was not sufficient to produce reliable and stable rates for trends. Moreover, comparison between them was often difficult due to the different diagnostic criteria adopted in the definition of events.

Within the MONICA Project (monitoring cardiovascular diseases) $[9,10]$, cerebrovascular events were monitored for 10 years in the Friuli-Venezia Giulia region. Fatal and nonfatal events were identified and validated applying standardized diagnostic criteria in men and women. The importance of this project lies in the fact that several countries were involved and adopted the same standardized procedures and methods in order to produce reliable and comparable data. This allowed to assess the disease trend and to detect differences within and among populations, despite the disparities due to the different health service organizations.

Attack Rates and Case Fatality for

Cerebrovascular Events

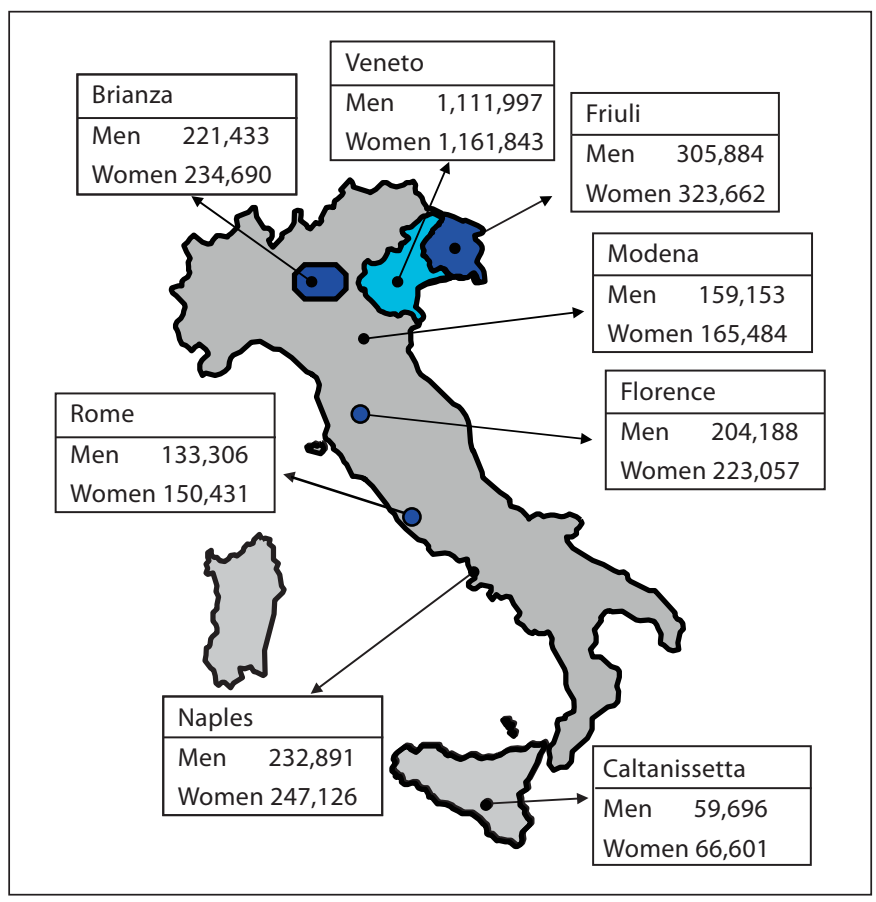

Fig. 1. Geographical distribution of the national register of cerebrovascular events.

However, such a surveillance system, although very informative, proved to be quite complex and too expensive to be maintained over time. Therefore, at the end of the 1990 s, a pilot surveillance system, based on the use of routine data and on the validation of a sample of suspected events, was implemented in different areas of the country in order to assess attack and case fatality rates and to compare them among different areas of the country [11, 12].

The present paper aims to illustrate the adopted methods and to report estimates of attack rates and 28-day case fatality rates for cerebrovascular events (fig. 1).

\section{Methods}

The surveillance system consists of 4 phases: (1) identification of current suspected cerebrovascular events; (2) validation of a sample of current suspected events; (3) assessment of positive predictive values (PPVs) of discharge and death ICD codes obtained by applying the diagnostic criteria from the MONICA Project; (4) calculation of estimated events through the application of PPVs to current events.

Identification of Current Suspected Cerebrovascular Events

To identify current nonfatal events, all those cases having codes of cerebrovascular accidents (ICD-9 342, 430-434, 436-438) as underlying or as any of the secondary discharge diagnoses were 
Fig. 2. Flowchart illustrating the methods of identification of cerebrovascular events.

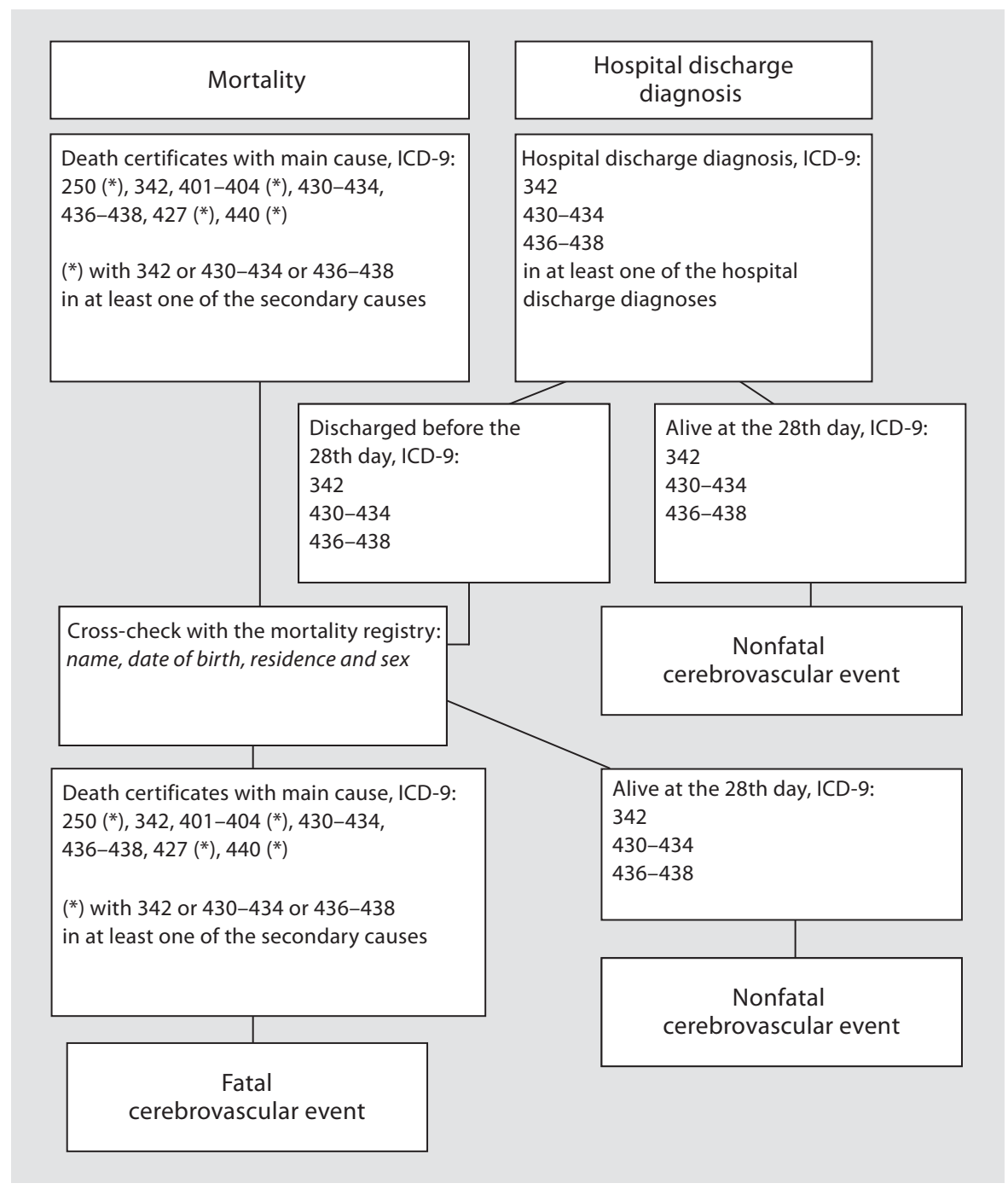

extracted from the hospital discharge records database. To identify current fatal events, all death certificates reporting cerebrovascular accident (ICD-9 342, 430-434, 436-438) as underlying cause of death, or diabetes (ICD-9250), hypertensive disease (ICD9 401-404), arrhythmia (ICD-9 427), atherosclerosis (ICD-9 440) as underlying cause of death associated with cerebrovascular accidents (ICD-9 342, 430-434, 436-438) in at least one of all secondary causes of death, were taken into account. Death certificates and hospital discharge diagnoses were linked to identify the events and to check duration (no more than 28 days from onset of symptoms), recurrent events and fatality (fig. 2). Record linkage is important since it avoids double counting, which may occur if the same event is registered more than once over the 28-day period in the hospital discharge database.

\section{Validation of a Sample of Current Suspected Events}

One thousand consecutive suspected events (500 for each year of surveillance) for each of the 8 registers were selected and validated through the revision of clinical documentation and the ap- plication of MONICA diagnostic criteria [11, 12], which defines a cerebrovascular event as 'rapidly developed clinical signs of focal (or global) disturbance of cerebral function lasting more than $24 \mathrm{~h}$ (except in cases of sudden death or if the development of symptoms is interrupted by a surgical intervention), with no apparent cause other than a vascular origin: it includes patients presenting clinical signs and symptoms suggestive of subarachnoid haemorrhage, intracerebral haemorrhage or cerebral ischaemic necrosis. Global clinical signs are accepted only in cases of subarachnoid haemorrhage or in patients with deep coma.' This definition does not include insufficiency of the systemic circulation such as shock, Stokes-Adams syndrome, and hypertensive encephalopathy. CT scan and MRI findings are not sufficient to define the event, which facilitates the comparison between inand out-of-hospital events.

Results of validation were then used to assess the PPVs for each single code of hospital discharge and cause of death as the proportion of validated events out of current events. 
Table 1. Analysis of diagnostic agreement between official cause of death codes and MONICA diagnostic aggregated category by gender

\begin{tabular}{|c|c|c|c|c|c|c|c|c|}
\hline \multirow[t]{3}{*}{ ICD-9 ${ }^{1}$} & \multicolumn{4}{|c|}{ Men } & \multicolumn{4}{|c|}{ Women } \\
\hline & \multicolumn{2}{|c|}{ MONICA fatal $\mathrm{CVA}^{2}$} & \multicolumn{2}{|c|}{ total } & \multicolumn{2}{|c|}{ MONICA fatal CVA ${ }^{2}$} & \multicolumn{2}{|c|}{ total } \\
\hline & $\mathrm{n}$ & PPV & $\mathrm{n}$ & prevalence & $\mathrm{n}$ & PPV & $\mathrm{n}$ & prevalence \\
\hline $250^{3}$ & 9 & 0.82 & 11 & 0.025 & 8 & 0.80 & 10 & 0.032 \\
\hline 342 & 4 & 0.67 & 6 & 0.014 & 1 & 0.33 & 3 & 0.010 \\
\hline $401-405^{3}$ & 9 & 0.69 & 13 & 0.030 & 7 & 0.70 & 10 & 0.032 \\
\hline $427^{3}$ & 1 & 1.00 & 1 & 0.002 & 3 & 0.75 & 4 & 0.013 \\
\hline 430 & 16 & 0.80 & 20 & 0.046 & 20 & 1.00 & 20 & 0.065 \\
\hline 431 & 73 & 0.76 & 96 & 0.222 & 53 & 0.87 & 61 & 0.198 \\
\hline 432 & 3 & 0.60 & 5 & 0.012 & 2 & 0.67 & 3 & 0.010 \\
\hline 433 & 2 & 1.00 & 2 & 0.005 & 3 & 1.00 & 3 & 0.010 \\
\hline 434 & 39 & 0.83 & 47 & 0.109 & 25 & 0.89 & 28 & 0.091 \\
\hline 436 & 83 & 0.74 & 112 & 0.259 & 59 & 0.71 & 83 & 0.269 \\
\hline 437 & 25 & 0.71 & 35 & 0.081 & 11 & 0.46 & 24 & 0.078 \\
\hline 438 & 4 & 0.33 & 12 & 0.028 & 6 & 0.86 & 7 & 0.023 \\
\hline $440^{3}$ & 2 & 0.67 & 3 & 0.007 & 0 & 0.00 & 0 & 0.000 \\
\hline Other $^{3}$ & 28 & 0.40 & 70 & 0.162 & 28 & 0.54 & 52 & 0.169 \\
\hline Total & 298 & 0.69 & 433 & & 226 & 0.73 & 308 & \\
\hline
\end{tabular}

Registered fatal cerebrovascular events in the 8 Italian areas over the entire observation period. CVA = Cerebrovascular accident.

${ }^{1}$ Underlying cause of death codes.

2 Fatal cerebrovascular event (MONICA diagnostic categories 'definite', 'associated with a definite or possible myocardial infarction', 'unclassifiable').

${ }^{3}$ With $342,430-434,436-438$ codes in other causes of death or discharge diagnoses.

\section{Estimation of Event Occurrence}

Estimation of event occurrence was obtained by applying the PPVs to the number of current events generated from the record linkage procedure and identified by the specific discharge or death codes according to the following formula:

$$
\mathrm{N}_{\mathrm{EE}}=\mathrm{N}_{\mathrm{CE}} \times \Sigma\left(\mathrm{VPP}_{\mathrm{i}} \times \operatorname{Pr}_{\mathrm{i}}\right)
$$

where $\mathrm{N}_{\mathrm{EE}}$ is the estimated number of events, $\mathrm{N}_{\mathrm{CE}}$ is the number of current events, $\mathrm{VPP}_{\mathrm{i}}$ is the PPV for a specific ICD-9 code and $\mathrm{Pr}_{i}$ is the prevalence of the specific ICD-9 code.

In this way, fatal and nonfatal current events were 'weighed' using PPVs specific for hospital discharge or death codes resulting from the validation procedure. Then, for each area, the estimated number of events was obtained and attack rates were calculated by dividing the estimated number of events by the area population per 10,000.

Age-specific rates were calculated as estimated events in each 10 -year age range $(35-44,45-54,55-64,65-74)$ divided by the corresponding population per 10,000 , where the estimated number of events was the result of the sum of estimated events for each single cause of death or hospital discharge in the same age range of each register. Case fatality rate was calculated as the ratio between the number of fatal events (in- and out-of-hospital deaths within 28 days from admission) and total number of cerebrovascular events.

Attack Rates and Case Fatality for

Cerebrovascular Events
Attack rates, case fatality rates and corresponding 95\% confidence intervals are reported by single area and 10 -year age range, for men and women separately. Attack rate was calculated as the mean value of a 2-year period (1998-1999 for all areas, 1997-1998 for Brianza). Attack rates and case fatality were age-standardized by a direct method, using the European standard population as a reference (men and women together to facilitate gender comparison).

Age-standardized attack rates and case fatality by geographical area were compared overall using the heterogeneity test $\left(\chi^{2}\right.$ test) and one by one with the total attack rate and case fatality of the total register using the test for comparison of proportions in big samples.

This system is described in detail in the protocol [11] and in the manual of operations [12]. It is based on the one proposed by Ferrario et al. $[13,14]$ for coronary event registration and is similar to the other one adopted and described by Spolaore $[15,16]$.

\section{Results}

The study involved 8 areas, distributed across northern, central and southern Italy: 3 of them covered a whole local health unit (Modena, Florence, Rome); 2 a 
Table 2. Analysis of diagnostic agreement between hospital discharge diagnosis codes and MONICA diagnostic aggregated category by gender

\begin{tabular}{|c|c|c|c|c|c|c|c|c|}
\hline \multirow[t]{3}{*}{ ICD-91 } & \multicolumn{4}{|c|}{ Men } & \multicolumn{4}{|c|}{ Women } \\
\hline & \multicolumn{2}{|c|}{ MONICA nonfatal CVA ${ }^{2}$} & \multicolumn{2}{|l|}{ total } & \multicolumn{2}{|c|}{ MONICA nonfatal CVA ${ }^{2}$} & \multicolumn{2}{|c|}{ total } \\
\hline & $\mathrm{n}$ & PPV & $\mathrm{n}$ & prevalence & $\mathrm{n}$ & PPV & $\mathrm{n}$ & prevalence \\
\hline 342 & 28 & 0.24 & 116 & 0.030 & 24 & 0.24 & 98 & 0.039 \\
\hline 430 & 47 & 0.72 & 65 & 0.017 & 71 & 0.74 & 96 & 0.038 \\
\hline 431 & 201 & 0.86 & 233 & 0.060 & 110 & 0.81 & 136 & 0.054 \\
\hline 432 & 41 & 0.60 & 68 & 0.018 & 14 & 0.54 & 26 & 0.010 \\
\hline 433 & 39 & 0.12 & 338 & 0.087 & 18 & 0.09 & 195 & 0.078 \\
\hline 434 & 585 & 0.81 & 726 & 0.188 & 354 & 0.78 & 455 & 0.181 \\
\hline 435 & 9 & 0.07 & 122 & 0.032 & 6 & 0.10 & 62 & 0.025 \\
\hline 436 & 219 & 0.61 & 360 & 0.093 & 180 & 0.67 & 269 & 0.107 \\
\hline 437 & 85 & 0.20 & 432 & 0.112 & 48 & 0.15 & 325 & 0.129 \\
\hline 438 & 11 & 0.07 & 158 & 0.041 & 7 & 0.07 & 103 & 0.041 \\
\hline Other ${ }^{3}$ & 96 & 0.08 & 1,251 & 0.323 & 76 & 0.10 & 749 & 0.298 \\
\hline Total & 1,361 & 0.35 & 3,869 & & 908 & 0.36 & 2,514 & \\
\hline
\end{tabular}

Registered nonfatal cerebrovascular events in the 8 Italian areas over the entire observation period. CVA = Cerebrovascular accident.

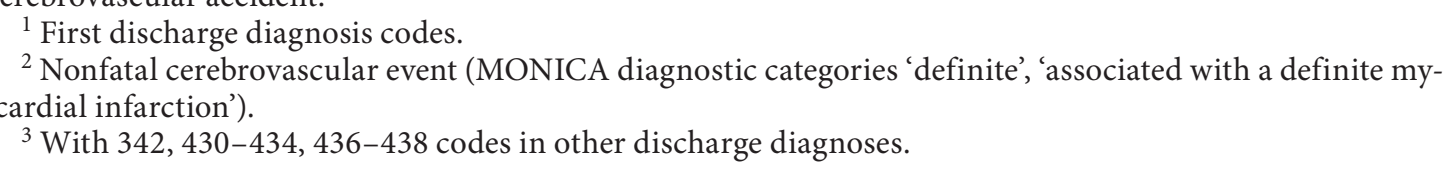

whole city (Napoli, Caltanissetta); Brianza covered a defined area of the Lombardia region; Friuli-Venezia Giulia and Veneto covered the whole region. Figure 1 shows the areas and populations under surveillance. About 5 million people were taken under surveillance for a 2year period.

\section{Diagnostic Agreement between Clinical and MONICA Categories}

PPVs were calculated for men and women separately in order to avoid gender influence; age-specific PPVs were calculated for each fatal and nonfatal ICD code for men and women separately. Tables 1 and 2 show the analysis of diagnostic agreement between selected ICD-9 codes and MONICA diagnostic aggregated categories, for fatal and nonfatal events, respectively. Data were provided by the 8 areas and all the events recorded over the entire observation period. Table 1 reports the underlying causes of death by gender reported on death certificates, coded according to the ICD rules and the validated MONICA diagnostic categories. Reported aggregations of ICD-9 codes were obtained through a sensitivity analysis, finalized to pool single ICD codes into ICD groups capable of generating the same proportion of MONICA events. For each ICD group the PPV is given, keeping the MONICA validated fatal cerebrovascular accident as a reference. For the purpose of this analysis, the MONICA diagnostic stroke categories 'definite', 'associated with a definite or possible myocardial infarction' or 'unclassifiable' are considered as positive for fatal cerebrovascular events. In men, high levels of diagnostic agreement were found among fatal events for ICD-9 code 434 (83\%) and diabetes mellitus (ICD-9 250; 82\%), followed by codes $430(80 \%)$ and $431(76 \%)$, then for code 436 (74\%); very low PPVs were found only for ICD code 438 and 'others' (33 and 40\%, respectively) indicating a considerable potential for generating MONICA validated fatal cerebrovascular accidents. In women, results were very similar, with high PPVs for ICD codes 430, 434, 431, 436, and 250 $(100,89,87,71$, and $80 \%$, respectively); ICD code 438 , unlike in men, presented a high PPV (86\%) even if events were very few.

Table 2 reports the results of the analysis of the diagnostic agreement between ICD-9 codes from main diagnoses of hospital discharges and MONICA diagnostic categories for nonfatal events, using data from the 8 Ital- 
Table 3. Attack rates $(\times 10,000)$ for fatal, nonfatal and total cerebrovascular events by 10 -year age groups and gender

\begin{tabular}{|c|c|c|c|c|c|}
\hline Age groups & $\begin{array}{l}\text { Total } \\
\text { estimated events }\end{array}$ & $\begin{array}{l}\text { Total } \\
\text { attack rates }\end{array}$ & $\begin{array}{l}\text { Fatal } \\
\text { attack rates }\end{array}$ & $\begin{array}{l}\text { Nonfatal } \\
\text { attack rates }\end{array}$ & $\begin{array}{l}\text { Ratio non- } \\
\text { fatal/fatal }\end{array}$ \\
\hline \multicolumn{6}{|l|}{ Men } \\
\hline $35-44(\mathrm{n}=743,359)$ & $277(245-310)$ & $2.4(2.2-2.7)$ & $0.4(0.2-0.5)$ & $2.1(1.8-2.3)$ & 5.8 \\
\hline $45-54(\mathrm{n}=659,452)$ & $911(852-970)$ & $9.0(8.4-9.5)$ & $1.2(1.0-1.4)$ & $7.8(7.3-8.3)$ & 6.7 \\
\hline $55-64(\mathrm{n}=586,976)$ & $2,478(2,381-2,576)$ & $27.3(26.2-28.4)$ & $3.7(3.3-4.1)$ & $23.7(22.7-24.7)$ & 6.5 \\
\hline $65-74(\mathrm{n}=438,761)$ & $5,339(5,196-5,481)$ & $78.2(76.1-80.2)$ & $14.6(13.7-15.5)$ & $63.5(61.6-65.4)$ & 4.3 \\
\hline Total & $9,005(8,819-9,191)$ & $24.0(23.5-24.5)$ & $4.0(3.8-4.2)$ & $20.1(19.6-20.5)$ & 5.0 \\
\hline STD total & & $21.9(21.4-22.4)$ & $3.6(3.4-3.8)$ & $18.3(17.9-18.8)$ & 5.1 \\
\hline \multicolumn{6}{|l|}{ Women } \\
\hline $35-44(\mathrm{n}=722,730)$ & $219(190-248)$ & $2.0(1.7-2.2)$ & $0.3(0.2-0.4)$ & $1.6(1.4-1.9)$ & 5.2 \\
\hline $45-54(\mathrm{n}=667,434)$ & $544(498-590)$ & $5.3(4.8-5.7)$ & $0.9(0.7-1.1)$ & $4.4(4.0-4.8)$ & 4.9 \\
\hline $55-64(\mathrm{n}=626,703)$ & $1,322(1,251-1,394)$ & $13.6(12.9-14.3)$ & $2.3(2.0-2.6)$ & $11.3(10.7-12.0)$ & 5.0 \\
\hline $65-74(\mathrm{n}=556,027)$ & $3,960(3,836-4,083)$ & $45.9(44.5-47.4)$ & $9.3(8.7-10.0)$ & $36.6(35.3-37.9)$ & 3.9 \\
\hline Total & $6,045(5,893-6,197)$ & $15.2(14.8-15.6)$ & $2.9(2.7-3.1)$ & $12.3(11.9-12.6)$ & 4.2 \\
\hline STD total & & $12.5(12.1-12.8)$ & $2.3(2.2-2.5)$ & $10.1(9.8-10.4)$ & 4.3 \\
\hline
\end{tabular}

STD total = Age-standardized with European standard population (men and women together). Figures in parentheses indicate 95\% confidence intervals.

ian areas. For the purpose of this analysis, the MONICA diagnostic stroke categories 'definite' or 'associated with a definite myocardial infarction' are considered as positive for nonfatal cerebrovascular events. Very different PPVs were found for the considered ICD codes, ranging from 86 and $81 \%$ for code 431 (intracerebral hemorrhage) in men and women, respectively, to $7 \%$ for code 435 (transient ischemic attack) in men and for code 438 (late effect of cerebrovascular disease) in both men and women.

\section{Attack Rates and Case Fatality}

Table 3 shows attack rates for total, fatal and nonfatal events by 10 -year age ranges, obtained by pooling the data of all areas. Attack rates were significantly higher in men than in women (about twofold higher considering the mean standardized value), particularly in the upper age group (78.2 vs. 45.9 per 10,000); they increased gradually with age and the ratio between nonfatal and fatal events decreased. Age-standardized attack rates by fatal, nonfatal and total cerebrovascular events by area are reported in table 4 for men and women separately. For each area, the ratio between attack rates for men and women ranged between 1.4 (Caltanissetta) and 2.3 (Florence) and resulted in a rate of 1.8 on average. There was evidence of significant heterogeneity in standardized attack rates among areas: in men values ranged from a maximum of 24.2 per 10,000 in Naples to a minimum of 14.7 per 10,000
Table 4. Age-standardized ${ }^{1}$ attack rates $(\times 10,000)$ for fatal, nonfatal and total cerebrovascular events by geographical area and gender (age range 35-74 years)

\begin{tabular}{llll}
\hline $\begin{array}{l}\text { Collaborative } \\
\text { unit }\end{array}$ & $\begin{array}{l}\text { Total attack } \\
\text { rates }\end{array}$ & $\begin{array}{l}\text { Fatal attack } \\
\text { rates }\end{array}$ & $\begin{array}{l}\text { Nonfatal attack } \\
\text { rates }\end{array}$ \\
\hline $\begin{array}{l}\text { Men } \\
\text { Brianza }\end{array}$ & $20.5(19.1-21.8)$ & $3.4(2.8-3.9)$ & $17.1(15.9-18.3)$ \\
Veneto & $21.7(20.8-22.5)$ & $2.4(2.1-2.7)$ & $19.3(18.5-20.1)$ \\
Friuli & $21.2(20.0-22.3)$ & $4.2(3.7-4.7)$ & $17.0(15.9-18.0)$ \\
Modena & $23.6(22.0-25.3)$ & $3.2(2.5-3.8)$ & $20.5(18.9-22.0)$ \\
Florence & $22.4(21.0-23.9)$ & $3.0(2.5-3.6)$ & $19.4(18.0-20.7)$ \\
Rome & $16.9(15.3-18.4)$ & $3.6(2.9-4.3)$ & $13.3(11.9-14.7)$ \\
Naples & $24.2(22.8-25.7)$ & $5.6(4.9-6.3)$ & $18.6(17.4-19.9)$ \\
Caltanissetta & $14.7(12.5-16.9)$ & $4.9(3.6-6.2)$ & $9.8(8.0-11.5)$ \\
\hline Women & & & \\
Brianza & $11.4(10.4-12.4)$ & $2.0(1.6-2.4)$ & $9.4(8.5-10.3)$ \\
Veneto & $11.5(10.9-12.1)$ & $1.4(1.1-1.6)$ & $10.2(9.6-10.8)$ \\
Friuli & $11.5(10.7-12.4)$ & $2.3(2.0-2.7)$ & $9.2(8.5-9.9)$ \\
Modena & $14.4(13.1-15.7)$ & $2.6(2.0-3.1)$ & $11.8(10.6-13.0)$ \\
Florence & $9.9(9.0-10.8)$ & $1.8(1.4-2.2)$ & $8.1(7.2-8.9)$ \\
Rome & $16.9(15.3-18.4)$ & $3.6(2.9-4.3)$ & $13.3(11.9-14.7)$ \\
Naples & $16.0(14.8-17.1)$ & $4.6(4.0-5.2)$ & $11.4(10.4-12.3)$ \\
Caltanissetta & $10.4(8.7-12.1)$ & $3.4(2.4-4.4)$ & $7.0(5.6-8.4)$ \\
\hline
\end{tabular}

Figures in parentheses indicate $95 \%$ confidence intervals.

${ }^{1}$ Age-standardized with European standard population (men and women together). 
Table 5. 28-day case fatality rates for cerebrovascular events by 10 -year age groups and gender

\begin{tabular}{llll}
\hline \multirow{2}{*}{ Age groups } & \multicolumn{2}{l}{ Case fatality rates, $\%$} & \multirow{2}{*}{ p value } \\
\cline { 2 - 3 } & men & women & \\
\hline $35-44$ & $14.8(10.6-18.9)$ & $16.1(11.3-21.0)$ & n.s. \\
$45-54$ & $13.0(10.8-15.2)$ & $16.9(13.7-20.0)$ & 0.0423 \\
$55-64$ & $13.4(12.1-14.7)$ & $16.7(14.7-18.7)$ & 0.0061 \\
$65-74$ & $18.7(17.7-19.8)$ & $20.3(19.1-21.6)$ & 0.05 \\
\hline Total & $16.5(15.8-17.3)$ & $19.1(18.1-20.1)$ & $<0.0001$ \\
STD total & $14.5(13.7-15.3)$ & $17.1(16.1-18.2)$ & $<0.0001$ \\
\hline
\end{tabular}

STD total $=$ Age-standardized with European standard population (men and women together). Figures in parentheses indicate 95\% confidence intervals.

Table 6. Crude and age-standardized 28-day case fatality rates for cerebrovascular events by register geographical area and gender (age range 35-74 years)

\begin{tabular}{|c|c|c|c|}
\hline & Men & Women & $\mathrm{p}$ value \\
\hline \multicolumn{4}{|c|}{ Crude case fatality rates, $\%$} \\
\hline Brianza & $16.5(14.1-18.9)$ & $17.5(14.5-20.5)$ & \\
\hline Veneto & $11.2(10.0-12.5)$ & $11.7(10.1-13.3)$ & \\
\hline Friuli & $20.0(18.0-22.1)$ & $20.4(17.8-23.0)$ & \\
\hline Modena & $13.7(11.4-16.1)$ & $18.8(15.6-21.9)$ & \\
\hline Florence & $13.6(11.6-15.7)$ & $18.9(15.7-22.1)$ & \\
\hline Rome & $21.7(18.1-25.3)$ & $25.2(20.7-29.6)$ & \\
\hline Naples & $23.5(21.1-25.9)$ & $29.1(26.1-32.1)$ & \\
\hline Caltanissetta & $35.2(28.7-41.8)$ & $33.9(26.8-41.0)$ & \\
\hline \multicolumn{4}{|c|}{ Age-standardized ${ }^{1}$ case fatality rates, $\%$} \\
\hline Brianza & $19.5(16.9-22.1)$ & $15.0(11.9-18.0)$ & 0.037 \\
\hline Veneto & $8.5(7.4-9.7)$ & $13.5(11.6-15.3)$ & $<0.0001$ \\
\hline Friuli & $16.4(14.4-18.4)$ & $21.2(18.2-24.1)$ & 0.008 \\
\hline Modena & $11.0(8.8-13.3)$ & $11.4(8.5-14.3)$ & n.s. \\
\hline Florence & $11.7(9.6-13.8)$ & $15.8(12.4-19.2)$ & 0.044 \\
\hline Rome & $17.6(14.1-21.1)$ & $24.1(19.3-29.0)$ & 0.038 \\
\hline Naples & $24.7(22.2-27.2)$ & $22.6(19.7-25.5)$ & n.s. \\
\hline Caltanissetta & $24.8(18.4-31.2)$ & $26.4(19.0-33.8)$ & n.s. \\
\hline
\end{tabular}

Figures in parentheses indicate $95 \%$ confidence intervals.

${ }^{1}$ Age-standardized with European standard population (men and women together).

in Caltanissetta; 4 areas showed standardized total attack rates significantly different from average (lower in Rome and Caltanissetta, higher in Naples and Modena); in all areas, except for Brianza, Friuli and Caltanissetta, attack rate among women was significantly different from the overall attack rate, with particularly high values in the areas of Rome (16.9 per 10,000) and Naples (16.0 per 10,000).

Table 5 shows 28 -day case fatality rates by age range, and crude and age-standardized total case fatality rates for men and women separately. In both genders, case fatality increases with age, particularly in the upper age group 65-74 years; case fatality rate was found to be statistically significantly higher in women than in men.

Table 6 shows both crude and age-standardized 28day case fatality by area of register, for men and women separately. In the areas of Veneto, Friuli, Florence and Rome, case fatality was statistically significantly higher in women than in men; the opposite was found in Brianza. Case fatality rates were particularly high in Rome, Naples, and Caltanissetta in both men and women; high case fatality rates were also registered in men from Brianza (19.5\%) and in women from Friuli (21.2\%). In all areas, case fatality was significantly different from total case fatality except for Friuli and Rome (men), and for Brianza and Florence (women).

\section{Discussion}

The objectives of a population-based register of cerebrovascular events are to evaluate the frequency, distribution and prognosis of the disease, to compare trends, changing patterns, and to monitor disease prevention programs. Using routinely data sources for the identification of events, validated on a sample basis, it is possible to obtain epidemiological estimates of attack rate and case fatality, indicators needed to monitor cerebrovascular disease occurrence in the community, to assess gender and age group differences for health service planning, to allocate appropriate resources and to evaluate effectiveness of preventive actions in the community. Total attack rate includes fatal and nonfatal cases, both first and recurrent events, providing an estimate of the burden of cerebrovascular diseases; it allows to monitor the disease trend in the community and shows the effects of welfare services and preventive measures adopted when outbreak of the disease occurs. Unfortunately, the registration system described here, based on the probabilistic estimation of event occurrence, does not allow to distinguish between first and recurrent events. In the future, the possibility of linking data related to previous years will allow to select the first-ever event and then calculate not only the attack rate, but also the disease incidence. This is useful if we consider that first events are related to risk fac- 
tors, their treatment, and lifestyles $[3,17,18]$, while recurrent events reflect the effects of care, rehabilitation, and secondary prevention [19].

Case fatality describes the appropriateness and effectiveness of treatment during the acute phase. Moreover, it may be influenced by other important factors, such as delay in the recovery, lifestyles and preventive treatments, which may affect the severity of events.

Attack rate for cerebrovascular events obtained through the national register was 21.9/10,000 in men and $12.5 / 10,000$ in women. Among men, the highest attack rates were found in Modena, Florence and Naples and among women in Modena, Rome, and Naples. In these areas, nonfatal attack rates mainly determined the differences in total attack rates, as fatal attack rates were basically comparable among all areas.

Official mortality referring to the same period of surveillance (1998-1999) differed significantly from fatal attack rates: age-standardized mortality was higher than cerebrovascular fatal attack rates in both men and women (about 41 and $32 \%$, respectively); mortality by age was systematically higher than fatal attack rates, from $20 \%$ in the age group 35-44 years to $44 \%$ in the oldest age group 65-74 years, even though increase by age was similar in both mortality and fatal attack rates (about 3 times moving from one age group to the following; data not shown). Official mortality was statistically different from cerebrovascular attack rates by registration area as well: in men, age-standardized mortality fell out of the confidence intervals (95\%) of fatal event attack rates for all areas; the same happened among women but only in 4 areas (Brianza, Veneto, Florence, and Caltanissetta). Several reasons may lie behind these differences: (1) registration areas did not exactly correspond to geographical country boundaries for which mortality data were available: this was the case of the metropolitan areas such as Rome and Naples which include only a limited area, while the official mortality data were available for the whole municipality; (2) the definition of the event within 28 days: it did not come from routine clinical practice, but from the MONICA Project and the WHO register; (3) the causes of death reported in death certificates were not validated; in that case death certificates could not refer to an acute event, but to sequelae.

Attack rates of stroke events reported for MONICAFriuli between 1984 and 1989 were 12.4/10,000 for men and 6.1/10,000 for women [20]; these values correspond to similar attack rates of the Italian cerebrovascular register considering the same age range (35-64 years): $12.3 / 10,000$ and $6.3 / 10,000$, respectively.

Attack Rates and Case Fatality for

Cerebrovascular Events
Data comparison with the registers of the Aosta Valley region and of the city of l'Aquila was not possible due to differences in age groups included, diagnostic criteria adopted in the definition of events, and covered area. These registers started for different purposes; they were basically prospective studies aiming at estimating the impact of stroke, understanding variation in the quality of care and outcome after stroke, and answering issues related to case mix and stroke health care, quality factors on the variations in health of stroke patients. Attack rates from the Italian register appeared, for the common age range, to be lower than those registered in the Aosta Valley region (men: 38/10,000 in the age range 55-64 and 98/10,000 in the upper one; women: $18 / 10,000$ and $63 / 10,000$ in the two age ranges, respectively) [6] and in the city of l'Aquila (men: 29/10,000 in the age range 55-64 and $97 / 10,000$ in the upper decade; women: 17/10,000 and $70 / 10,000$, respectively) [7].

The overall standardized 28-day case fatality rates were $14.5 \%$ for men and $17.1 \%$ for women. They were found to be lower than those reported from other studies, even when considering both genders together: $20 \%$ in the Aosta Valley region, and $26 \%$ in the city of l'Aquila. It is clear that this difference was not due to a different criterion (30-day case fatality instead of 28-day case fatality) but to a different identification and validation of the event instead.

A north-south gradient in case fatality was not evident even if the highest values were registered in Naples and Caltanissetta for both men and women. Socioeconomic conditions and educational level, which are not determined in this study, could contribute to explain higher case fatality in these areas.

In those areas where attack rates were found particularly low, there was evidence of a greater heterogeneity in case fatality rate among men compared with women (even though not significant). This finding was of great relevance since women under surveillance, being more numerous than men and with less events occurring in the age range 35-74 years, were less subjected to casual fluctuations.

Population-based monitoring of cerebrovascular events involves a number of problems, the most important being the completeness of case ascertainment. This is especially true for population areas where many stroke patients are not diagnosed or treated in hospital. There were marked differences in attack rates among areas, which seemed mostly related to different rates for nonfatal events (table 4); probably in the area of Caltanissetta, lack of ascertainment of nonhospitalized nonfatal events

Cerebrovasc Dis 2007;24:530-539 
could contribute to explain very low nonfatal attack rates in both men and women. In the Italian areas of the MONICA Project (Friuli for 10 years and Latina for 3 years only), the proportion of out-of-hospital stroke was basically null; this means that all nonfatal cases received treatment in hospital or nursing home [21,22]. Even if MONICA data referred to out-of-hospital strokes in the age range 35-64 years, we can assume high admission rates for stroke for the participating areas also in the wider age range considered (35-74 years). We think that in the area of Caltanissetta the population under surveillance was not wide enough to produce stable estimates of attack rates.

It should be highlighted that during the first years of activity of the MONICA Project attack rates registered in the area of Latina, representing the south-center of Italy, were relatively lower than those registered in Friuli, while the case fatality rate was higher [22]. The south of Italy has always been considered a low-risk area for coronary heart disease, but higher for stroke [2]. Unfortunately, the reported data demonstrate that the disease frequency is increasing in the south and particularly in urban areas such as Naples, where attack rates were observed to be higher in both men and women. The average high level of blood pressure, the high prevalence of current smokers and the high frequency of obesity in the population of the south of Italy may be some of the reasons behind the increase in disease frequency. Data from the Osservatorio Epidemiologico Cardiovascolare [23] showed an average blood pressure at a 'high normal' level in the south of Italy in both men and women (systolic blood pressure 134 $\mathrm{mm} \mathrm{Hg}$ in men and $133 \mathrm{~mm} \mathrm{Hg}$ in women; diastolic blood pressure $85 \mathrm{~mm} \mathrm{Hg}$ and $83 \mathrm{~mm} \mathrm{Hg}$, respectively) [24]; high prevalence of current smokers (34\% in men and $20 \%$ in women in the south in comparison to 30 and $20 \%$ at the national level) and a high frequency of obesity (19\% in men and $31 \%$ in women in the south in comparison to 18 and $22 \%$ at the national level) [23].

In recent years, the availability of hospital discharge records and death certificates in electronic format has facilitated the event identification through the record linkage between databases. The Italian register is based on record linkage of administrative data, performed after an accurate quality control of mortality and hospital discharge databases. In addition, this register includes validation which provides the means to:

- avoid biases deriving from different procedures adopted in case history coding in different areas;

- collect extensive information on events, monitor use of treatments, and diagnostic tools;
- ensure data comparability within the register (different subpopulations and different time points);

- ensure data comparability with other registers within the country;

- ensure international comparability.

Taking into account comparisons of results with official mortality data, MONICA Register data for Italian areas, and with results from Aosta and l'Aquila registers, the experience of the national register of cerebrovascular events confirms the feasibility and potential of a national surveillance system based on record linkage of routine data and on validation of a sample of events implemented in some representative areas of the country.

Some issues have arisen and require in-depth analysis in order to improve the surveillance system:

- the age range is limited; even though the register included a further age decade with respect to the MONICA Project (which limited the registration of events to the age range 35-64 years), the representativeness of the general population is still not assured, especially for pathologies such as cerebrovascular diseases which particularly affect the elderly; indeed, among hospitalized patients, the prevalence of patients over 75 with cerebrovascular diseases is not irrelevant;

- the choice of the geographical area to be taken under surveillance depends on the event occurrence; following the recommendations proposed by the European Cardiovascular Indicators Surveillance Set (EUROCISS) Project funded by the EU Commission under the Health Monitoring Program [25], the minimal number of 300 total events per year in the age range 45-74 years is needed to produce reliable rates;

- the implementation is not cheap; thus, a periodical collection (e.g. 1 year each 5) could be performed in order to evaluate possible trends;

- collection and coding of secondary causes of deaths are necessary but difficult since only the underlying cause is codified and available in electronic support;

- the fatal and nonfatal 500 events to be validated could be selected considering several days during the year in order to take into account possible seasonal variability.

These issues reflect recommendations deriving from the EUROCISS Project [25], which have the main objective of producing manuals of operations for implementing population-based stroke registers following standardized methodologies in order to produce comparable data at the European level. 


\section{Acknowledgements}

Research group of the project 'Italian National Register of Major Coronary and Cerebrovascular Events': Istituto Superiore di Sanità (coordinating center): Luigi Palmieri, Francesco Dima, Cinzia Lo Noce, Paola Ciccarelli, Simona Giampaoli; Brianza area: Giancarlo Cesana, Lauretta Bolognesi, Marco Ferrario; Friuli area: Diego Vanuzzo, Lorenza Pilotto; Veneto area: Paolo Spolaore, Francesco Avossa, Elena Schievano, Cristiana Visentin, Stefano Brocco; Modena area: Carlo Alberto Goldoni, Gianfranco De Girolamo, Alessandra Schiavi, Rita Rielli; Florence area: Eva Buiatti, Alessandro Barchielli, Daniela Balzi, Paola Naldoni; Rome area: Massimo Uguccioni, Francesco Forastiere, Nerina
Agabiti, Giovanna Giovannozzi, Milva Gatti, Daniela D’Ippoliti; Naples area: Enrico de Campora, Salvatore Panico, Sergio Lodato, Andrea Simonetti, Marina Di Gennaro, Assunta Lombardo, Amalia Mattiello; Caltanissetta area: Federico Vancheri, Anna Maria Giuffrida, Maddalena Curcio, Paola Sidoti. The research was carried out within the following projects financed by the Ministry of Health: 'Implementation of Italian National Register of Coronary and Cerebrovascular Events' coordinated by ISS, 'Italian National Register of Major Coronary and Cerebrovascular Events: Proposal to Set Up a National Surveillance System' coordinated by the Region of Sicily, and 'CUORE Project II: Assessment of Individual Risk, Prognostic Therapeutic Structures and Approaches for CVD'.

\section{References}

1 http://www.iss.it/site/mortalita/Scripts/SelCause.asp.

2 Giampaoli S: Le malattie del sistema circolatorio e il diabete; in Istituto Nazionale di Statistica (eds): La mortalità in Italia nel periodo 1970-1992: evoluzione e geografia. Roma, Istituto Nazionale di Statistica, Istituto Superiore di Sanità, 1999, pp 169-209.

$\checkmark 3$ Giampaoli S, Palmieri L, Panico S, Vanuzzo D, Ferrario M, Chiodini P, Pilotto L, Donfrancesco C, Cesana G, Sega R, Stamler J: Favorable cardiovascular risk profile (low risk) and 10-year stroke incidence in women and men: findings on twelve Italian population samples. Am J Epidemiol 2006;163:893902.

-4 EUROCISS Working Group: Coronary and cerebrovascular population-based registers in Europe: are morbidity indicators comparable? Results from the EUROCISS Project. Eur J Public Health 2003;13(suppl):55-60.

5 Kjellström T, Norrving B, Shatchkute A: Helsingborg Declaration 2006 on European stroke strategies. Cerebrovasc Dis 2007;23: 229-241.

6 D’Alessandro G, Bottacchi E, Di Giovanni M, Martinazzo C, Sironi L, Lia C, Carenino L, Corso G, Gerbaz V, Polillo C, Pesenti Compagnoni M: Temporal trends of stroke in Valle d'Aosta, Italy. Incidence and 30day fatality rates. Neurol Sci 2000;21:1318.

7 Carolei A, Marini C, Di Napoli M, Di Gianfilippo G, Santalucia P, Baldassarre M, De Matteis G, di Orio F: High stroke incidence in the prospective community-based L'Aquila registry (1994-1998). First year's results. Stroke 1997;28:2500-2506.

8 Schmal M, Marini C, Carolei A, Di Napoli M, Kessels F, Lodder J: Different vascular risk factor profiles among cortical infarcts, small deep infarcts, and primary intracerebral haemorrhage point to different types of underlying vasculopathy. A study from the L'Aquila Stroke Registry. Cerebrovasc Dis 1998;8:14-19.
9 Asplund K, Tuomilehto J, Stegmayr B, Wester PO, Tunstall-Pedoe H: Diagnostic criteria and quality control of the registration of stroke events in the MONICA project. Acta Med Scand 1988;728(suppl):26-39.

10 Tunstall-Pedoe $\mathrm{H}$; for the WHO MONICA Project: MONICA. Monograph and Multimedia Sourcebook. The World's Largest Study of Heart Disease, Stroke, Risk Factors, and Population Trends (1979-2002). Geneva, World Health Organization, 2003.

11 Ferrario M, Giampaoli S, Vancheri F, Vanuzzo D: Registro per gli eventi coronarici e cerebrovascolari: protocollo dello studio. Rapporti ISTISAN 2001;01/8:1-89.

12 Palmieri L, Dima F, Bolognesi L, et al; e il Gruppo di ricerca del Registro nazionale degli eventi coronarici e cerebrovascolari maggiori: Registro per gli eventi coronarici e cerebrovascolari. Manuale delle operazioni. Rapporti ISTISAN 2003;35:1-151.

13 Ferrario M, Cesana G, Vanuzzo D, Pilotto L, Sega R, Chiodini P, Giampaoli S: Surveillance of ischaemic heart disease: results from the Italian MONICA populations. Intern J Epidemiol 2001;30:S23-S29.

14 Ferrario M, Cesana G, Vanuzzo D, Pilotto L, Sega R, Chiodini P, Giampaoli S: Sorveglianza epidemiologica della occorrenza della cardiopatia ischemica: risultati dalle aree MONICA italiane e proposta di un modello semplificato di stima. G Ital Cardiol 1999; 29(suppl 2):161-167.

15 Williams GR, Jiang JC, Matchar DB, Samsa GP: Incidence and occurrence of total (firstever and recurrent) stroke. Stroke 1999;30: 2523-2528.

16 Spolaore P, Brocco S, Fedeli U, Visentin C, Schievano E, Avossa F, Milan G, Toso V, Vanuzzo D, Pilotto L, Pessina AC, Bonita R: Measuring accuracy of discharge diagnoses for a region-wide surveillance of hospitalized strokes. Stroke 2005;36:1031-1034.

-17 Stegmayr B, Asplund K, Kuulasmaa K, Rajakangas AM, Thorvaldsen P, Tuomilehto J; for the WHO MONICA Project: Stroke inci- dence and mortality correlated to stroke risk factors in the WHO MONICA Project. An ecological study of 18 populations. Stroke 1997;28:1367-1374.

18 Tolonen H, Mähönen M, Asplund K, Rastenyte D, Kuulasmaa K, Vanuzzo D, Tuomilehto J; for the WHO MONICA Project: Do trends in population levels of blood pressure and other cardiovascular risk factors explain trends in stroke event rates? Comparisons of 15 populations in 9 countries within the WHO MONICA Stroke Project. Stroke 2002; 33:2367-2375.

19 Asplund K, Rajakangas AM, Kuulasmaa K, Thorvaldsen P, Bonita R, Stegmayr B, Suzuki K, Eisenblätter D; for the WHO MONICA Project: Multinational comparison of diagnostic procedures and management of acute stroke - The WHO MONICA Study. Cerebrovasc Dis 1996;6:66-74.

20 Thorvaldsen P, Kuulasmaa K, Rajakangas AM, Rastenyte D, Sarti C, Wilhelmsen L: Stroke trends in the WHO MONICA project. Stroke 1997;28:500-506.

21 Asplund K, Bonita R, Kuulasmaa K, Rajakangas AM, Feigin V, Schaedlich H, Suzuki $\mathrm{K}$, Thorvaldsen $\mathrm{P}$, Tuomilehto $\mathrm{J}$; for the WHO MONICA Project: Multinational comparisons of stroke epidemiology. Stroke 1995;26:355-360.

22 Giampaoli S, Menotti A, Rigetti G, Verdecchia A: Register for cerebrovascular events in the Area Latina, Italy. Clinical and epidemiological data during three years of surveillance. Ital J Neurol Sci 1989;10:499-503.

23 Giampaoli S, Vanuzzo D; Il Progetto CUORE-Osservatorio Epidemiologico Cardiovascolare Italiano: Atlante italiano delle malattie cardiovascolari, II Edizione 2004. Ital Heart J 2004;5(suppl 3):49S-93S.

24 Guidelines Committee: 2003 European Society of Hypertension-European Society of Cardiology guidelines for the management of arterial hypertension. J Hypertens 2003; 21:1011-1053.

25 http://www.iss.cuore.it/EUROCISS. 